\title{
Decreased expression of interferon-induced protein 2 (IFIT2) by $W n t / \beta$-catenin signaling confers anti-apoptotic properties to colorectal cancer cells
}

\author{
Tomoyuki Ohsugi ${ }^{1}$, Kiyoshi Yamaguchi ${ }^{1}$, Chi Zhu ${ }^{1}$, Tsuneo Ikenoue ${ }^{1}$ and Yoichi \\ Furukawa $^{1}$ \\ ${ }^{1}$ Division of Clinical Genome Research, Advanced Clinical Research Center, Institute of Medical Science, The University of \\ Tokyo, Minato-ku, Tokyo 108-8639, Japan \\ Correspondence to: Kiyoshi Yamaguchi, email: kiyamagu@ims.u-tokyo.ac.jp \\ Keywords: IFIT2; colorectal cancer; Wnt; $\beta$-catenin; apoptosis \\ Received: June 06, $2017 \quad$ Accepted: October 02, 2017 \\ Published: October 26, 2017 \\ Copyright: Ohsugi et al. This is an open-access article distributed under the terms of the Creative Commons Attribution License \\ 3.0 (CC BY 3.0), which permits unrestricted use, distribution, and reproduction in any medium, provided the original author and \\ source are credited.
}

\section{ABSTRACT}

Impaired Wnt signaling pathway plays a crucial role in the development of colorectal cancer through activation of the $\beta$-catenin/TCF7L2 complex. Although genes up-regulated by $W n t / \beta$-catenin signaling have been intensively studied, the roles of down-regulated genes are poorly understood. In this study, we explored a global gene expression of colorectal cancer cells transfected with $\beta$-catenin siRNAs or a dominant negative form of TCF7L2 (dnTCF7L2), and identified a set of genes down-regulated by $W n t / \beta$-catenin signaling. Among the genes, we focused here on IFIT2, a gene encoding interferon-induced protein with tetratricopeptide repeats. A reporter assay using plasmids containing a 5'-flanking region of the gene showed that the reporter activity was enhanced by either transduction of $\beta$-catenin siRNA or dnTCF7L2, suggesting that the region is involved in the transcriptional regulation as a downstream of the $\beta$-catenin/TCF7L2 complex. Consistent with this result, expression of IFIT2 was significantly lower in colorectal cancer tissues than that in normal tissues. Exogenous IFIT2 expression decreased cell proliferation and increased apoptosis of colorectal cancer cells. These data suggested that the down-regulation of IFIT2 by $W n t / \beta$-catenin signaling may play a vital role in human colorectal carcinogenesis through the suppression of apoptosis.

\section{INTRODUCTION}

Wnt signaling pathway is associated with maintenance of organogenesis, growth, and homeostasis through the regulation of differentiation, proliferation, and cell fate of epithelial cells [1]. Aberrant Wnt signaling has been linked to many diseases including cancer, fibrosis, and neurodegeneration diseases [2]. One of the key mediators in this pathway is $\beta$-catenin. In the absence of Wnt signaling, a multi-molecular complex comprising of $\beta$-catenin, APC, Axin, and GSK-3 $\beta$ phosphorylates $\beta$-catenin, leading to its degradation in a proteasome-dependent pathway [3]. Upon the binding of Wnt ligands to Frizzled receptors and low density lipoprotein receptor-related protein, Dishevelled proteins are activated and inhibit the activity of GSK-3 $\beta$ [4]. Consequently, degradation of $\beta$-catenin is suppressed, and the accumulated $\beta$-catenin is translocated into the nucleus, where it binds to transcription factors such as T-cell factor/lymphoid enhancer factor (TCF/LEF). The TCF/LEF family is then activated and transactivates the expression of their target genes. In $93 \%$ of colorectal tumors, Wnt/ $\beta$-catenin signaling is deregulated mainly due to the inactivation of $A P C$ or activating mutations of $C T N N B 1$ [5], which results in the elevated expression of target genes of the $\beta$-catenin/TCF complex.

Many efforts have been made to identify direct downstream targets of $\beta$-catenin/TCF such as c-myc 
[6], cyclin D1 [7], MMP-7 (matrilysin) [8], LGR5 [9], urokinase-type plasminogen activator receptor (UPAR) [10], connexin 43 [11], CD44 [12], AF17 [13], ENC1 [14], Laminin-5 $\gamma 2$ [15], PPAR-delta [16], Claudin-1 [17], and MT1-MMP [18]. To date, regulatory mechanisms and molecular functions of these target genes have been well studied in cancer cells. For example, c-myc [19] and cyclin D1 [20] regulate cell proliferation and cell cycles progression, respectively. LGR5 is involved in the maintenance of stemness [21]. Functional analyses of these target genes have contributed to understanding the role of $\beta$-catenin-dependent Wnt signaling in carcinogenesis. However, the roles of down-regulated downstream genes by the signaling remain largely unknown.

The interferon-induced proteins with tetratricopeptide repeats (IFITs) consist of four members, IFIT1, IFIT2, IFIT3, and IFIT5, in humans. Induced by interferons, or through the membrane-bound Toll-like receptors (TLRs), or the cytoplasmic RIG-1-like receptors (RLRs), IFITs play a crucial role in host antiviral defense as an innate immune response. IFIT1 and IFIT2 bind to the multi-subunit eukaryotic translation initiation factor 3 (eIF3) [22], interfere with the assembly of the preinitiation complex containing the 40S ribosomal subunit, eIF3, eIF2/GTP/Met-tRNA, and eIF4F [23], and inhibit translation initiation. In addition, IFIT1, IFIT2 and IFIT3 form a complex that recognizes viral RNA lacking 2'-O methylation on their cap structures or displaying a 5 '-triphosphate group (PPP-RNA), a molecular signature that distinguishes viral RNA from host RNA [24]. Interestingly, IFIT1 and IFIT2 associate with MITA (mediator of IRF3 activation), and induce apoptosis via the mitochondrial pathway $[25,26]$. Moreover, IFIT2 elicits apoptotic cell death independent of IFN stimulation [26]. On the other hand, IFIT3 interacts with IFIT2, and negatively regulates the apoptotic effects of IFIT2 [22]. Although roles of IFITs in viral infection have been intensively investigated, studies regarding their roles in carcinogenesis have been limited.

In this study, we identified IFIT1 and IFIT2 as genes down-regulated by Wnt signaling in colorectal cancer (CRC) cells, and clarified that inhibition of IFIT2 may play a role in the proliferation and anti-apoptotic properties of CRC cells. Our findings may be helpful for the profound understanding of colorectal carcinogenesis.

\section{RESULTS}

\section{Genes down-regulated by the $\beta$-catenin/TCF7L2 complex in CRC}

To identify genes down-regulated by the $\beta$-catenin/ TCF7L2 complex, we searched for those up-regulated by the suppression of $\beta$-catenin or TCF7L2. First, we performed gene expression profile analyses of SW480 and HCT116 cells treated with $\beta$-catenin siRNA or control
siRNA. These analyses identified 781 and 1636 entities whose expression levels were elevated greater than twofold by the $\beta$-catenin siRNA compared with control siRNA in HCT116 and SW480 cells, respectively. In addition, we identified 772 entities whose expression was enhanced more than two-fold by a dominant-negative form of TCF7L2 (dnTCF7L2) in LS174T cells using public expression profile data (GSE46465) [27]. Taking these data together, we identified a total of 54 entities that were commonly up-regulated in response to the suppression of the $\beta$-catenin/TCF7L2 complex (Figure 1A and Supplementary Table 1). The 54 entities include 53 genes and one non-coding RNA, and the top 20 genes induced by the suppression of the complex are shown in Table 1 .

\section{Biological significance of a set of genes down- regulated by the complex}

To understand the biological significance of genes down-regulated by the activation of Wnt-signaling in the cells, Gene Set Enrichment Analysis were carried out with curated gene sets in the Molecular Signatures Database (http://software.broadinstitute.org/gsea/msigdb/index.jsp), and the 54 down-regulated entities were analyzed (Table $2)$. The genes were found to be significantly associated with interferon signaling, cytokine signaling in the immune system, and interferon- $\alpha / \beta$ signaling, suggesting that Wnt signaling might affect interferon-mediated immune responses.

\section{Expression of IFITs in CRC}

We found that two interferon-induced genes, IFIT1 and IFIT2, were included in the top 20 in the list of downregulated genes (Table 1). In addition, IFIT3 was in the top 30 genes. Subsequent quantitative RT-PCR analysis determined that knockdown of $\beta$-catenin by siRNA increased IFIT1 (15.5-fold), IFIT2 (7.8-fold), and IFIT3 (3.4-fold) expression, compared with control siRNA in SW480 cells (Figure 1B).

Since activation of the $\beta$-catenin/TCF7L2 complex is a frequent feature observed in CRC, we compared expression of IFIT1, IFIT2, and IFIT3, and that of MYC and $C C N D 1$, two direct target genes of the complex, between colorectal tumor tissues and normal colonic mucosae using the Oncomine cancer profiling database (GSE20916 in https://www.oncomine.org). As shown in Figure 1C, expression levels of MYC and CCND1 were significantly elevated in tumor tissues than those in normal tissues (2.80-fold with MYC probe \#202431, $p=4.0 \times 10^{-14} ; 1.91$-fold with CCND1 probe \#208711, $p=8.96 \times 10^{-7}$; and 2.11-fold with $C C N D 1$ probe $\# 208712$, $p=8.79 \times 10^{-9}$ ). On the other hand, expression levels of IFIT1 and IFIT2 were significantly down-regulated in colorectal adenocarcinoma compared with normal tissues (-3.95-fold with IFIT1 probe \#203153, $p=6.3 \times 10^{-13}$; 
-1.42-fold with IFIT2 probe \#217502, $p=2.91 \times 10^{-8}$, and -2.40-fold with IFIT2 probe \#226757, $p=1.1 \times 10^{-12}$ ) [28]. In addition, two datasets (GSE4183 [29] and GSE8671 [30]) revealed that expression levels of IFIT1 and IFIT2 were also down-regulated in colorectal adenoma tissues compared with normal tissues (Supplementary Figure 1). However, the expression of IFIT3 was not significantly altered (-1.11-fold, $p=0.17$ with IFIT3 probe \#204747: and -1.23-fold with IFIT3 probe $\# 229450, p=0.12$ ) in colorectal adenocarcinoma (Figure 1C), suggesting that other factor(s) may be involved in the regulation of IFIT3 expression in colorectal tumors. Western blotting corroborated that knockdown of $\beta$-catenin increased IFIT1 and IFIT2 proteins in SW480, HCT116, LS174T, and DLD-1 cells. (Figure 1D). These data indicated that IFIT1 and IFIT2 proteins are down-regulated in colorectal cancer cells by Wnt signaling.

To clarify the negative regulation of IFIT1 and IFIT2 by the Wnt signaling, we introduced an activating form of $\beta$-catenin lacking exon3 (pcDNA-CTNN1B $\Delta$ exon3)
[31] into HeLa cells that have normal Wnt signaling pathway, and analyzed $A X I N 2$ expression that is another target of the $\beta$-catenin/TCF7L2 complex. Quantitative RT-PCR analysis determined that overexpression of $\beta$-catenin increased $A X I N 2$ expression by 16 -fold and that it reduced expression of IFIT1 and IFIT2 (0.3-fold and 0.4-fold, respectively) (Supplementary Figure 2). These data strengthened that the expression of IFIT1 and IFIT2 is negatively regulated by Wnt signaling.

\section{Regulation of IFIT1 and IFIT2 promoter activities}

To clarify transcriptional regulation of IFITI and IFIT2 by the $\beta$-catenin/TCF7L 2 complex, we carried out a reporter assay using plasmids containing their 5 '-flanking regions (pIFIT1 -627/+22 and pIFIT2 $-1366 /+169$ ) in SW480 cells. Dual-luciferase assay revealed that the reporter activity of pIFIT1 was augmented 1.92- and 1.88fold by $\beta$-catenin siRNA\#9 and siRNA\#10, respectively,
A

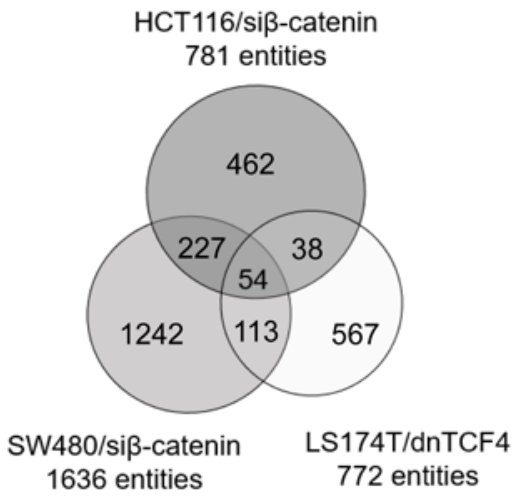

C

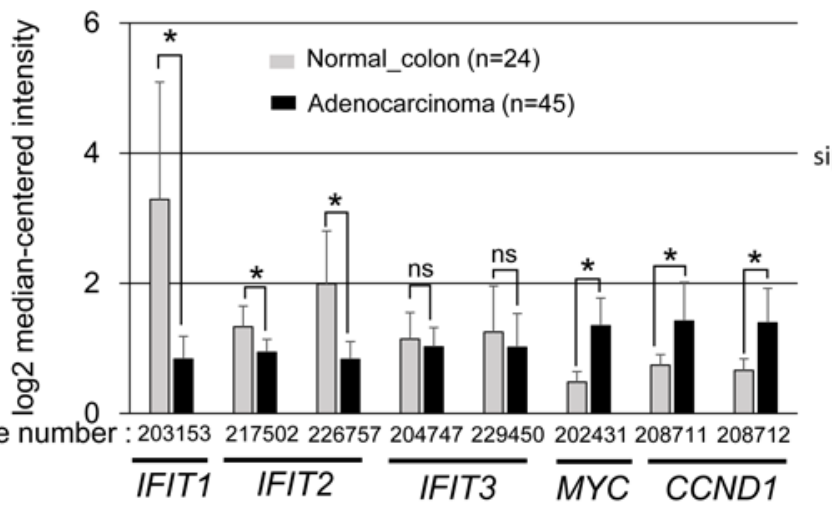

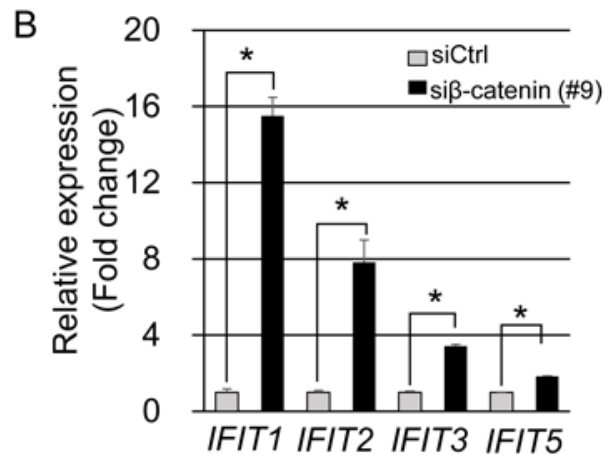

D

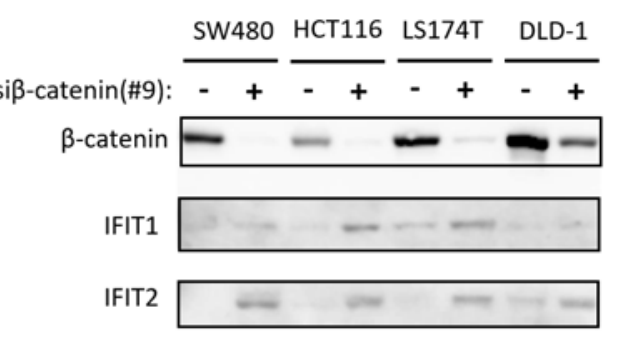

$\beta$-actin ----

Figure 1: Identification of IFIT1 and IFIT2 as downstream genes repressed by Wnt/ $\boldsymbol{\beta}$-catenin. (A) Integration of three microarray data identified 53 commonly upregulated genes and one non-coding RNA by inhibition of the $\beta$-catenin/TCF7L2 complex. (B) Expression levels of IFITs in SW480 cells treated with $\beta$-catenin or control siRNA for $48 \mathrm{~h}$ were determined by real time-PCR. Expression of $G A P D H$ was used as an internal control. The data represents mean \pm SD from three experiments. Asterisk indicates $p<0.05$. (C) Expression of IFIT1, IFIT2, IFIT3, MYC, and CCND1 in CRC tissues obtained from a public database, Gene Expression Atlas (GSE20916). (D) Increased IFIT 1 and IFIT2 proteins by the knockdown of $\beta$-catenin in CRC cell lines. The lysates from CRC cells transfected with $\beta$-catenin or control siRNA for $48 \mathrm{~h}$ were subjected to western blotting. Expression of $\beta$-actin served as an internal control. 
Table 1: List of the top 20 up-regulated genes in CRC cells treated with $\beta$-catenin or dnTCF7L2

\begin{tabular}{|c|c|c|c|c|c|}
\hline \multirow{2}{*}{\multicolumn{2}{|c|}{ Gene symbol }} & \multicolumn{4}{|c|}{ Fold change } \\
\hline & & \multirow{2}{*}{$\frac{\text { SW480 (si } \beta \text {-catenin) }}{40.67}$} & \multirow{2}{*}{$\frac{\text { HCT116 (si } \beta \text {-catenin) }}{4.71}$} & \multirow{2}{*}{$\frac{\text { LS174T (dnTCF7L2) }}{10.60}$} & \multirow{2}{*}{$\frac{\text { Average }}{18.66}$} \\
\hline 1 & ANGPTL4 & & & & \\
\hline \multirow[t]{3}{*}{2} & ANXA8 & 32.78 & 2.31 & 5.38 & 13.49 \\
\hline & $A N X A 8 L 1$ & & & & \\
\hline & $A N X A 8 L 2$ & & & & \\
\hline \multirow[t]{2}{*}{3} & $A N X A 8 L 2$ & 32.78 & 2.31 & 5.25 & 13.45 \\
\hline & $A N X A 8 L 1$ & & & & \\
\hline 4 & KPNA7 & 23.81 & 13.93 & 2.52 & 13.42 \\
\hline \multirow[t]{2}{*}{5} & $A N X A 8 L 1$ & 32.78 & 2.31 & 4.53 & 13.21 \\
\hline & $A N X A 8 L 2$ & & & & \\
\hline 6 & IFIT1 & 20.39 & 3.13 & 5.26 & 9.59 \\
\hline 7 & C10orf10 & 18.29 & 4.39 & 2.73 & 8.47 \\
\hline 8 & $M B$ & 2.08 & 12.68 & 10.24 & 8.34 \\
\hline 9 & CD68 & 2.79 & 4.88 & 16.45 & 8.04 \\
\hline 10 & $P L A U$ & 8.62 & 3.22 & 11.18 & 7.67 \\
\hline 11 & KLHL30 & 7.34 & 9.08 & 4.31 & 6.91 \\
\hline 12 & IFIT2 & 11.36 & 3.89 & 5.31 & 6.86 \\
\hline 13 & PTAFR & 7.03 & 2.07 & 11.37 & 6.82 \\
\hline 14 & $H M O X 1$ & 3.30 & 4.79 & 9.99 & 6.02 \\
\hline 15 & $B M F$ & 4.20 & 2.65 & 11.03 & 5.96 \\
\hline 16 & $F G F B P 1$ & 9.59 & 4.67 & 3.24 & 5.83 \\
\hline 17 & $A H N A K 2$ & 5.52 & 3.26 & 7.93 & 5.57 \\
\hline 18 & $E L F 3$ & 7.73 & 3.95 & 4.38 & 5.36 \\
\hline 19 & APOL6 & 3.00 & 10.06 & 2.18 & 5.08 \\
\hline 20 & $M V P$ & 9.27 & 2.64 & 2.22 & 4.71 \\
\hline
\end{tabular}

Genes were sorted based on average fold changes across the three conditions.

and that of pIFIT2 was augmented 2.62- and 1.98-fold by siRNA\#9 and siRNA\#10, respectively (Figure 2A). To examine whether $\beta$-catenin can repress the enhanced expression and reporter activities of IFIT1 and IFIT2, we transfected the cells with plasmids that express the activating mutant form of $\beta$-catenin lacking exon3 together with $\beta$-catenin siRNA\#12 that targets a sequence in exon3. As shown in Figure 2B, the enhanced reporter activities of IFIT1 and IFIT2 by $\beta$-catenin siRNA\#12 were suppressed in part by the expression of $\beta$-catenin, supporting that $\beta$-catenin play a suppressive role in the transcriptional activities of IFIT1 and IFIT2 in CRC cells. Since $\beta$-catenin has been known to function as a coactivator of TCF transcription factors, we assume that IFIT1 and IFIT2 are down regulated by $\beta$-catenin/TCF complex through unknown mechanism(s). Two prediction programs, JASPAR (http://jaspar.genereg.net/) and TFBIND (http:// tfbind.hgc.jp/), did not predict TCF/LEF binding motif(s) in their promoter regions (data not shown).

\section{Involvement of IFIT2 in apoptosis}

To explore the function of IFIT1 and IFIT2 in CRC cells, we established SW480 and HCT116 cells that stably express exogenous IFIT1 and IFIT2 using the retrovirus transduction system. Exogenous expression of IFIT2, but not IFIT1, significantly suppressed the proliferation of SW480 and HCT116 cells (Figure 3A and 3B). Subsequent cell cycle analysis revealed that their overexpression did not alter the population of G1, S, or G2/M phases. 
Table 2: Gene Set Enrichment Analysis of up-regulated genes by suppression of the $\beta$-catenin/TCF complex

\begin{tabular}{|c|c|c|c|c|c|}
\hline Gene Set & Description & $\begin{array}{l}\text { Genes in } \\
\text { Overlap }\end{array}$ & Gene symbol & p value & FDR \\
\hline $\begin{array}{l}\text { REACTOME_} \\
\text { INTERFERON_SIGNALING }\end{array}$ & Interferon signaling & 4 & IFIT1, IFIT2, IFIT3, PTAFR & $2.38 \mathrm{e}-5$ & 2.83 e- 2 \\
\hline $\begin{array}{l}\text { REACTOME_- } \\
\text { INTERFERON_ALPHA_- } \\
\text { BETA_SIGNALIALING }\end{array}$ & Interferon $\alpha / \beta$ signaling & 3 & IFIT1, IFIT2, IFIT3 & $4.26 \mathrm{e}-5$ & $2.83 \mathrm{e}-2$ \\
\hline NABA_MATRISOME & $\begin{array}{l}\text { Extracellular matrix } \\
\text { and extracellular } \\
\text { matrix -associated } \\
\text { proteins }\end{array}$ & 7 & $\begin{array}{c}F G F 1, P L A U, A N G P T L 4, \\
F G F B P 1, S E M A 7 A \\
\text { SEMA4B, LAMB3 }\end{array}$ & $9.09 \mathrm{e}-4$ & $4.03 \mathrm{e}-2$ \\
\hline $\begin{array}{l}\text { NABA_MATRISOME_ } \\
\text { ASSOCIATED }\end{array}$ & $\begin{array}{l}\text { ECM-associated } \\
\text { proteins including } \\
\text { ECM-affilaited } \\
\text { proteins, ECM } \\
\text { regulators and secreted } \\
\text { factors }\end{array}$ & 6 & $\begin{array}{c}F G F 1, P L A U, A N G P T L 4 \\
F G F B P 1, S E M A 7 A \\
\text { SEMA4B }\end{array}$ & $1.3 \mathrm{e}-4$ & $4.31 \mathrm{e}-2$ \\
\hline $\begin{array}{l}\text { REACTOME_CYTOKINE_- } \\
\text { SIGNALING_IN_IMMUNE_- } \\
\text { NE SYSTEM }\end{array}$ & $\begin{array}{l}\text { Cytokine signaling in } \\
\text { immune system }\end{array}$ & 4 & IFIT1, IFIT2, IFIT3, PTAFR & $1.85 \mathrm{e}-4$ & $4.92 \mathrm{e}-2$ \\
\hline
\end{tabular}

A

\section{Reporter constructs:}
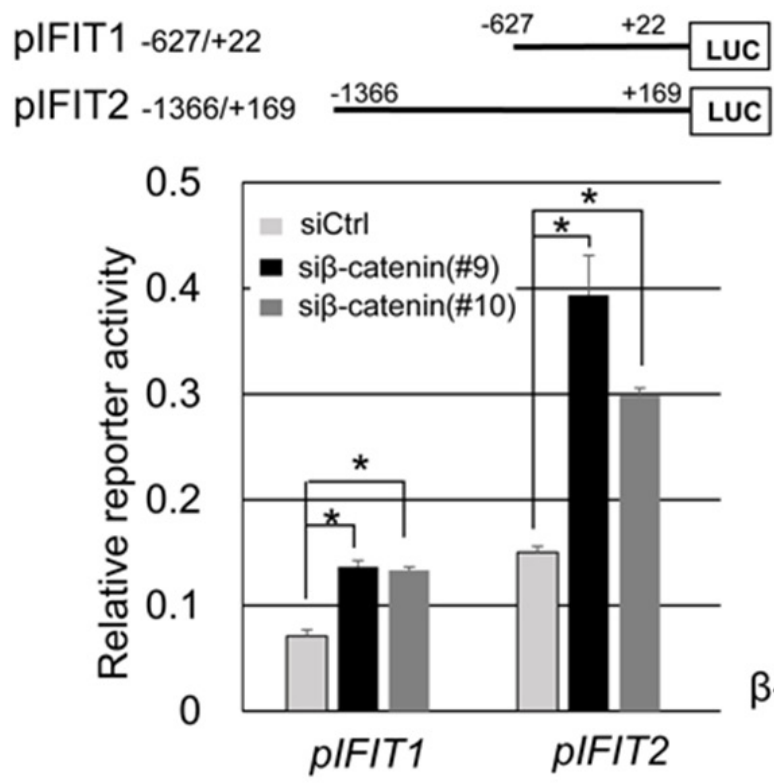

B

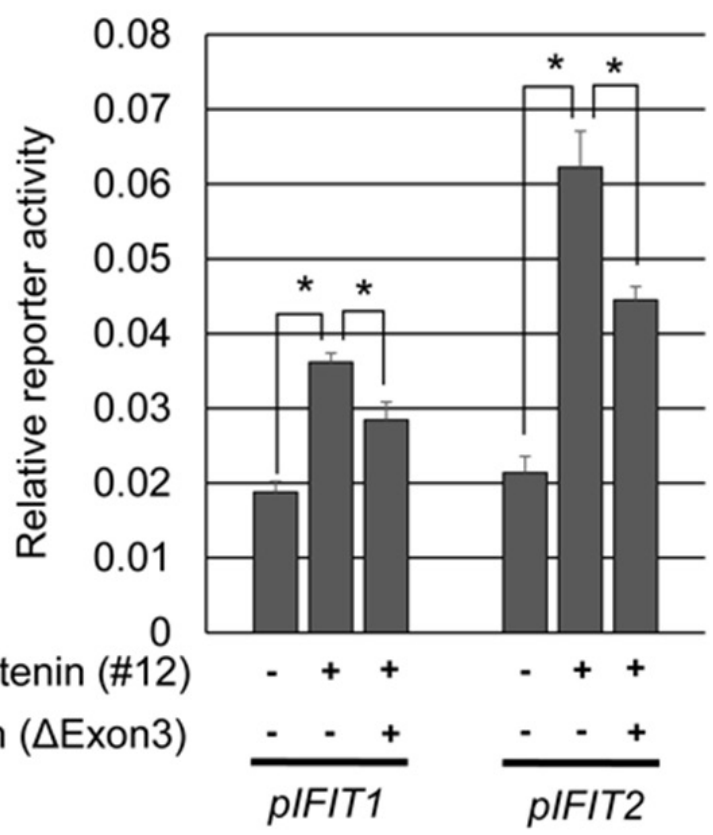

Figure 2: Association between the reporter activities of IFIT1 and IFIT2, and $\beta$-catenin expression. (A) Reporter activities of pIFIT1 and pIFIT2 in the presence or absence of $\beta$-catenin siRNA in SW480 cells. The cells were transfected with the indicated reporter plasmids in combination with different $\beta$-catenin siRNAs (\#9 or \#10) or control siRNA. The data represents mean \pm SD from three experiments. An asterisk indicates $p<0.05$. (B) Suppression of the induced reporter activities of pIFIT1 and pIFIT2 by $\beta$-catenin siRNA (\#12) with an activating mutant form of $\beta$-catenin in SW480 cells. The mutant form of $\beta$-catenin lacks the sequence targeted by $\beta$-catenin siRNA (\#12), and thus is not suppressed by the siRNA. The luciferase activities represent mean \pm SD from three-independent cultures. An asterisk indicates $p<0.05$. 
A

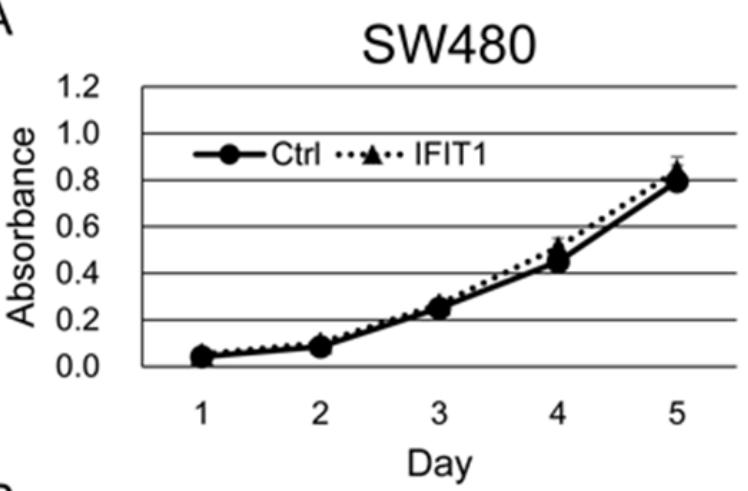

B
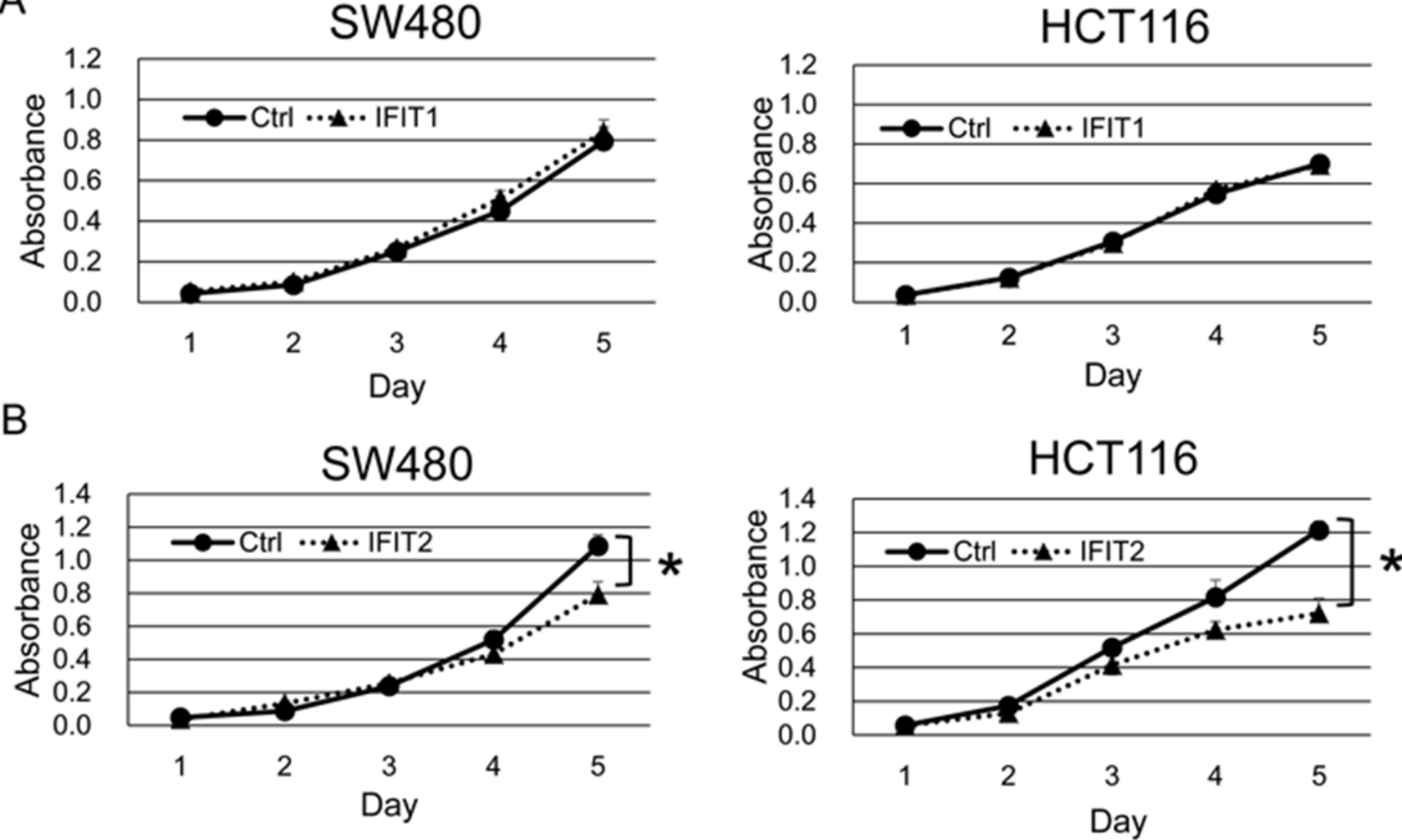

Figure 3: Effect of IFIT1 and IFIT2 on proliferation of CRC cells. The proliferation of SW480 and HCT116 cells stably expressing IFIT1 (A) or IFIT2 (B) was measured by WST-8 assay. A significant difference was determined by two-way ANOVA.
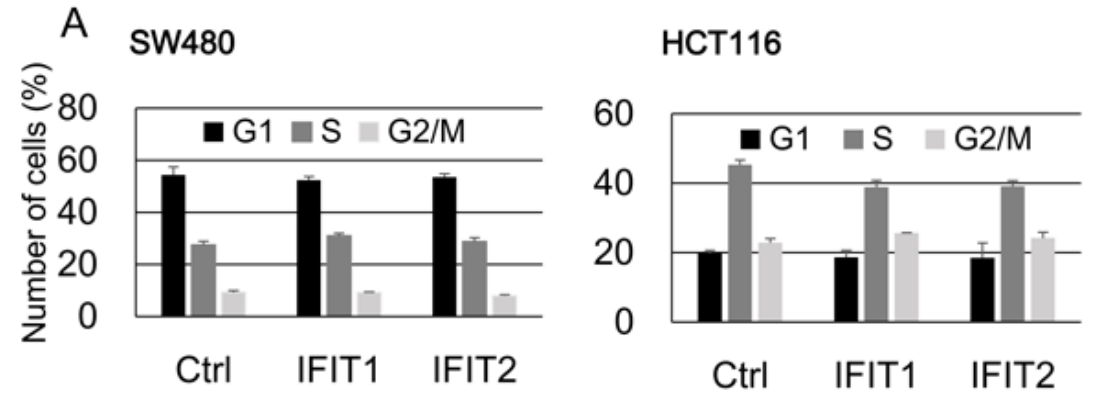

C
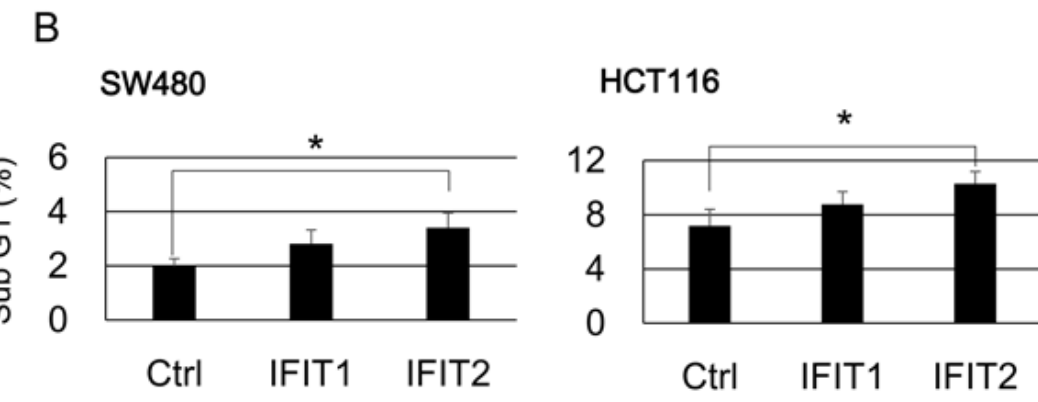

cleaved-caspase 8

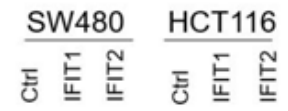


However, the sub-G1 population was significantly increased by IFIT2 in SW480 and HCT116 cells (Figure $4 \mathrm{~A}$ and $4 \mathrm{~B}$ ), suggesting that induction of apoptosis by IFIT2 may be associated with the suppressed growth of CRC cells. In addition, we found that overexpression of IFIT2 increased the expression of BAX and cleaved forms of caspase- 8 and PARP in SW480 and HCT116 cells, suggesting that IFIT2 may increase the sensitivity of cells to apoptosis through the mitochondria pathway. However, cleaved form of caspase- 3 was not detected in HCT116 cells but detected in SW480 cells. Response of procaspase-3 to IFIT2 might be different between SW480 and HCT116 cells (Figure 4C). On the other hand, IFIT2 did not enhance the apoptosis induced by camptothecin (an inhibitor of topoisomerase I) or $\gamma$-irradiation in SW480 and HCT116 cells (Supplementary Figure 3). These data imply that IFIT2 might not affect the cell viability to DNA-damaging insults.

\section{DISCUSSION}

In this study, we discovered that IFIT1 and IFIT2 are negatively regulated by Wnt signaling in CRC cells and that suppressed expression of IFIT2 may confer prosurvival properties to cancer cells.

IFIT2 or ISG54 (Interferon stimulated gene 54) is a protein of approximately $54 \mathrm{kDa}$, which forms a complex with IFIT1 and IFIT3. Stawowczyk and colleagues reported that exogenous expression of IFIT2 suppressed proliferation of HeLa cells and promoted their cell death through apoptosis [26]. They also found that Bak and/or Bax were indispensable for the IFIT2-inducted apoptosis, and that Bcl-xl prevented the induction of apoptosis. These results suggested that IFIT2 stimulated apoptosis through the regulation of mitochondrial membrane permeability. In agreement with their view, overexpression of IFIT2 increased the expression of BAX, and cleaved forms of PPAR and caspase- 8 in CRC cells, suggesting that IFIT2 plays a role in the apoptosis via mitochondria-mediated pathway. Therefore, reduced expression of IFIT2 might render anti-apoptotic properties to colorectal cancer cells.

Of note, they additionally showed that IFIT3 but not IFIT1 counteracted the induction of apoptosis by IFIT2. Since activation of Wnt signaling in cancer cells decreased both IFIT1 and IFIT2, co-repression of these genes may confer the pro-survival properties to the cancer cells by increasing resistance to apoptotic signals. We found that the effect of aberrant Wnt signaling on the repression of IFIT3 is mild compared to that of IFIT1 and IFIT2, and that IFIT3 expression was not decreased in CRC tissues. These data may imply that IFIT1 and IFIT2 are the main targets of Wnt signaling among the human IFITs in CRC.

In addition, Feng et al. reported that IFIT2 is posttranscriptionally regulated by miR-645, a microRNA that is abundantly expressed in adenocarcinoma of gastric esophageal junction (AGEJ) [32]. They proved that the expression levels of IFIT2 were negatively correlated with those of miR-645 in clinical AGEJ tissues, and showed that IFIT2 expression was significantly lower in tumors greater than five centimeters in size compared with those less than five. Importantly, they found that exogenous expression of IFIT2 significantly suppressed the growth of gastric cancer cells, and promoted apoptosis in the cells treated with Adriamycin. Recently, another group reported that LINC00161, a long non-coding RNA, sensitized cisplatin-induced apoptosis through the modulation of the miR-645-IFIT2 pathway in osteosarcoma [33]. These data suggest that decreased expression of IFIT2 may confer growth advantage and anti-apoptotic characteristics to cancer cells, which is in good agreement with our findings in this study.

Importantly, this is the first report showing that IFIT1 and IFIT2 are negatively regulated by Wnt signaling in colon cancer. Expression of IFITs are induced by viral and bacterial infection [34], type I IFN including IFN$\alpha / \beta$ [35], and a variety of cellular stresses such as DNA damage [36]. Although IFIT2 expression is regulated by miR-645 in a post-transcriptional manner as described previously, signal transduction pathways including IFN $\beta$ dependent pathways, IFN-regulatory factor 3 (IRF3)dependent pathways, NF-кB pathway, and JAK-STAT pathway are involved in the regulation of IFITs expression [22]. In addition, IFIT2 is also induced by the recruitment of IRF transcription factors such as IRF1, IRF3, IRF5, IRF7, and IRF9 [37-40]. Future studies may disclose a novel link between Wnt signaling and IFN-regulatory factors.

Although IFIT1 and IFIT2 may not be direct targets of the $\beta$-catenin/TCF transcriptional complex, suppressed expression of these molecules may be involved in carcinogenesis through the activation of antiapoptotic properties. Further studies of their regulation may contribute to a better understanding of colorectal carcinogenesis and the development of strategies to enhance apoptotic effect of anti-cancer drugs.

\section{MATERIALS AND METHODS}

\section{Cell culture}

Human CRC cell lines, HCT116, SW480, DLD-1, LS174T and human cervix cell lines, HeLa were purchased from the American Type Culture Collection (Manassas, VA). All cells were grown in appropriate media (McCoy's 5a Medium Modified for HCT116; RPMI-1640 for DLD-1; Leibovitz's L-15 for SW480; EMEM for HepG2, HeLa, and LS174T) supplemented with 10\% FBS (ThermoFisher, Waltham, MA), and antibiotic/antimycotic solution (Sigma, St. Louis, MO). 


\section{Gene silencing}

Three $\beta$-catenin siRNAs (ON-TARGETplus SMARTpool siRNA L-003482-00, \#9, \#10, and \#12) and control siRNA (ON-TARGETplus Non-targeting Pool \#D-001810-10) were purchased from GE Dharmacon (Lafayette, CO). Target sequences of the siRNAs are shown in Supplementary Table 2. HCT116 or SW480 were seeded a day before the treatment with siRNA, and transfected with $15 \mathrm{nM}$ of $\beta$-catenin or control siRNA using Lipofectamine RNAiMAX (Thermo Fisher Scientific). Forty-eight hours after the transfection, RNA and proteins were extracted from the cells. The silencing effect of $\beta$-catenin siRNAs was evaluated by quantitative RT-PCR and western blotting.

\section{Gene expression analysis}

Total RNA was extracted from the cells treated with $\beta$-catenin or control siRNA using RNeasy Plus mini Kit (Qiagen, Valensia, CA), and RNA integrity was assessed by 2100 Bioanalyzer (Agilent Technologies, Santa Clara, CA). Two-hundred microgram of total RNA were amplified and labeled using a Low Input QuickAmp Labeling Kit according to the manufacturer's protocols (Agilent Technologies). Expression profiles were analyzed using SurePrint G3 Human Gene Expression 8x60K Microarray according to the supplier's recommendations (Agilent Technologies). Subsequent data processing was performed using the GeneSpring GX13.1 (Agilent Technologies). Additionally, gene set enrichment analysis was performed using the Molecular signatures database (MSigDB, http://www.broadinstitute.org/gsea/msigdb/ index.jsp) with gene sets derived from Canonical pathways, BioCarta, KEGG, and Reactome.

\section{Quantitative PCR}

Complementary DNA (cDNA) was synthesized from one $\mu \mathrm{g}$ of total RNA with Transcriptor First Strand cDNA Synthesis Kit (Roche Diagnostics GmbH, Mannheim, Germany). Real-time PCR was performed using qPCR Kapa SYBR Fast ABI Prism Kit (Kapa Biosystems, Wilmington, MA) with sets of primers for IFIT1, IFIT2, and IFIT3 on StepOnePlus (Thermo Fisher Scientific). Sequences of the primers used are shown in Supplementary Table 3. The levels of transcripts were determined by the relative standard curve method, and $G A P D H$ was used as internal control.

\section{Western blotting}

Total protein was extracted from cultured cells using radioimmunoprecipitation assay (RIPA) buffer $(50 \mathrm{mM}$ Tris- $\mathrm{HCl}$, pH8.0, $150 \mathrm{mM}$ sodium chloride, $0.5 \%$ sodium deoxycholate, $0.1 \%$ sodium dodecyl sulfate, $1.0 \%$ NP- 40 ) supplemented with a Protease Inhibitor Cocktail Set III
(Calbiochem, San Diego, CA). Protein concentration was determined by BCA Protein Assay Kit (Thermo Scientific, Rockford, IL). Protein (30-50 $\mu \mathrm{g} /$ lane) was separated by $10 \%$ SDS-PAGE and transferred on to a nitrocellulose membrane (GE Healthcare, Buckinghamshire, UK). After the blocking with 5\% milk powder in TBS-T ( Trisbuffered saline - Tween20) for 1 hour, the membranes were incubated over night with primary antibodies including anti- $\beta$-catenin (9582, Cell Signaling Technology, Danvers, MA), anti- $\beta$-actin (A5441, Sigma), anti-IFIT1 (HPA055380, sigma), anti-IFIT2 (12604-1-AP, Proteintech Group, Chicago, MA), anti-PARP (9532, Cell Signaling Technology), anti-cleaved PARP (9541, Cell Signaling Technology), anti-Bax (sc-493, Santa Cruz Biotechnology, Dallas, TX), anti-Bak (sc-832, Santa Cruz Biotechnology), anti-caspase-3 (9662, Cell Signaling Technology), and anti-caspase-8 antibodies (M032-3, MBL, Nagoya, Japan). Horseradish peroxidase-conjugated goat anti-mouse or anti-rabbit IgG (GE Healthcare) served as the secondary antibody for the ECL Detection System (GE Healthcare).

\section{Reporter assay}

The 5'-flanking regions of IFIT1 $(-627 /+22)$ and IFIT2 $(-1366 /+169)$ were amplified by PCR, and the DNA fragments were cloned into pGL3-Basic vector (Promega, Madison, WI) to generate reporter plasmids (pIFIT1 -627/+22 and pIFIT2 -1366/+169, respectively). The primer sequences are shown in Supplementary Table 4. Cells were transfected with the reporter plasmids and pRL-TK (Promega) in combination with control or $\beta$ catenin siRNA. Reporter assay was carried out using a dual-luciferase reporter assay system (Toyo Ink, Tokyo, Japan) according to the supplier's recommendations.

\section{Retroviral transduction}

The pMXs retroviral vectors carrying the IFITI and IFIT2 genes were constructed by the insertion of DNA fragments encoding full-length IFITI (NM_001548) and IFIT2 (NM_001547), respectively. The primer sequences used for the amplification are shown in Supplementary Table 4. Retroviral particles were produced by the transfection of PLAT-A packaging cells with pMXIFIT1, pMX-IFIT2, or pMX-EGFP (a kind gift from Dr. Kitamura, The University of Tokyo). Culture supernatants containing the retrovirus were collected and used to transduce the RNA in the CRC cells. The cells expressing each gene were selected in medium containing puromycin (HCT116: $1 \mu \mathrm{g} / \mathrm{ml}$ and SW480: $2.5 \mu \mathrm{g} / \mathrm{ml}$ ).

\section{Cell cycle analysis}

SW480 and HCT116 cells stably expressing IFIT1, IFIT2, or control EGFP were fixed with $70 \%$ ethanol at $-20^{\circ} \mathrm{C}$. The cells were treated with RNase A $(2 \mathrm{mg} / \mathrm{ml})$ at $37^{\circ} \mathrm{C}$ for $30 \mathrm{~min}$, and incubated with propidium iodide 
$(20 \mu \mathrm{g} / \mathrm{ml})$ in PBS at room temperature for $30 \mathrm{~min}$. After filtration with nylon mesh, the cells were applied for flow cytometric analysis (FACSCalibur, BD Biosciences, Franklin Lakes, NJ).

\section{Cell proliferation assay}

Cell proliferation assay was carried out by water soluble tetrazolium salts (WST)-based colorimetric method using Cell-counting kit-8 according to the supplier's protocol (Dojindo, Kumamoto, Japan). Absorbance was measured at $450 \mathrm{~nm}$ using FLUOstar OPTIMA (BMG Labtechnologies, GmbH, Germany).

\section{Statistical analysis}

Statistical analysis was performed by Student's t-test with Benjamini-Hochberg correction for the analysis of gene expression profiles. The unpaired Student's t-test and Dunnett's test were used for the statistical analysis of RTPCR and reporter assay data. The data of cell proliferation was analyzed by two-way ANOVA.

\section{Author contributions}

$\mathrm{KY}$ and YF developed the study design; TO performed all the experiments. TO, CZ, KY, TI, and YF interpreted data. TO wrote the draft of the manuscript, and KY and YF revised the manuscript.

\section{ACKNOWLEDGMENTS}

We are grateful to Seira Hatakeyama, Rika Koubo, and Yumiko Ishii (The University of Tokyo) for their technical assistance.

\section{CONFLICTS OF INTEREST}

All authors have no conflicts of interest.

\section{FUNDING}

This work was supported in part by the Grant-in-Aid (\#17H03575) from the Japan Society for the Promotion of Science.

\section{REFERENCES}

1. Siegel R, Naishadham D, Jemal A. Cancer statistics, 2013. CA Cancer J Clin. 2013; 63:11-30. https://doi.org/10.3322/ caac. 21166.

2. Kahn M. Can we safely target the WNT pathway? Nat Rev Drug Discov. 2014; 13:513-32. https://doi.org/10.1038/ $\operatorname{nrd} 4233$.

3. Rubinfeld B, Albert I, Porfiri E, Fiol C, Munemitsu S, Polakis P. Binding of GSK3beta to the APC-beta-catenin complex and regulation of complex assembly. Science. 1996; 272:1023-6.

4. Polakis P. Wnt signaling and cancer. Genes Dev. 2000; 14:1837-51. https://doi.org/10.1101/gad.14.15.1837.

5. Cancer Genome Atlas Network. Comprehensive molecular characterization of human colon and rectal cancer. Nature. 2012; 487:330-7. https://doi.org/10.1038/nature11252.

6. He TC, Sparks AB, Rago C, Hermeking H, Zawel L, da Costa LT, Morin PJ, Vogelstein B, Kinzler KW. Identification of c-MYC as a target of the APC pathway. Science. 1998; 281:1509-12. https://doi.org/10.1126/ science.281.5382.1509.

7. Tetsu O, McCormick F. Beta-catenin regulates expression of cyclin D1 in colon carcinoma cells. Nature. 1999; 398:422-6. https://doi.org/10.1038/18884.

8. Brabletz T, Jung A, Dag S, Hlubek F, Kirchner T. $\beta$-Catenin Regulates the Expression of the Matrix Metalloproteinase-7 in Human Colorectal Cancer. Am J Pathol. 1999; 155:10338. https://doi.org/10.1016/S0002-9440(10)65204-2.

9. Barker N, van Es JH, Kuipers J, Kujala P, van den Born M, Cozijnsen M, Haegebarth A, Korving J, Begthel H, Peters PJ, Clevers H. Identification of stem cells in small intestine and colon by marker gene Lgr5. Nature. 2007; 449:1003-7. https://doi.org/10.1038/nature06196.

10. Mann B, Gelos M, Siedow A, Hanski ML, Gratchev A, Ilyas M, Bodmer WF, Moyer MP, Riecken EO, Buhr HJ, Hanski C. Target genes of beta-catenin-T cell-factor/lymphoidenhancer-factor signaling in human colorectal carcinomas. Proc Natl Acad Sci U S A. 1999; 96:1603-8.

11. van der Heyden MA, Rook MB, Hermans MM, Rijksen G, Boonstra J, Defize LH, Destrée OH. Identification of connexin43 as a functional target for Wnt signalling. J Cell Sci. 1998; 111:1741-9.

12. Wielenga VJ, Smits R, Korinek V, Smit L, Kielman M, Fodde R, Clevers H, Pals ST. Expression of CD44 in Apc and Tcf mutant mice implies regulation by the WNT pathway. Am J Pathol. 1999; 154:515-23. https://doi. org/10.1016/S0002-9440(10)65297-2.

13. Lin $\mathrm{Y}$, Ono K, Satoh S, Ishiguro H, Fujita M, Miwa N, Tanaka T, Tsunoda T, Yang K, Nakamura Y, Furukawa Y. Advances in Brief Identification of AF17 As a Downstream Gene of the $\beta$-catenin/T-Cell Factor Pathway and Its Involvement in Colorectal Carcinogenesis 1. Science. 2001; 6345-9.

14. Fujita M, Furukawa Y, Tsunoda T, Tanaka T, Ogawa M, Nakamura Y. Up-regulation of the ectodermal-neural cortex 1 (ENC1) gene, a downstream target of the $\beta$-catenin/T-cell factor complex, in colorectal carcinomas. Cancer Res. 2001; 61:7722-6.

15. Hlubek F, Jung A, Kotzor N, Kirchner T, Brabletz T. Expression of the invasion factor laminin $\gamma 2$ in colorectal carcinomas is regulated by $\beta$-catenin. Cancer Res. 2001; 61:8089-93.

16. He TC, Chan TA, Vogelstein B, Kinzler KW. PPARdelta is an APC-regulated target of nonsteroidal anti-inflammatory 
drugs. Cell. 1999; 99:335-45. https://doi.org/ S0092-8674(00)81664-5.

17. Miwa N, Furuse M, Tsukita S, Niikawa N, Nakamura Y, Furukawa Y. Involvement of Claudin- 1 in the $\beta$-Catenin/Tcf Signaling Pathway and its Frequent Upregulation in Human Colorectal Cancers. Oncol Res. 2001; 12:469-76. https:// doi.org/10.3727/096504001108747477.

18. Takahashi M, Tsunoda T, Seiki M, Nakamura Y, Furukawa Y. Identification of membrane-type matrix metalloproteinase-1 as a target of the beta-catenin/Tcf4 complex in human colorectal cancers. Oncogene. 2002; 21:5861-7. https://doi.org/10.1038/sj.onc.1205755.

19. Sansom OJ, Meniel VS, Muncan V, Phesse TJ, Wilkins JA, Reed KR, Vass JK, Athineos D, Clevers H, Clarke AR. Myc deletion rescues Apc deficiency in the small intestine. Nature. 2007; 446:676-9. https://doi.org/10.1038/ nature 05674 .

20. McCormick F, Tetsu O. [beta]-Catenin regulates expression of cyclin D1 in colon carcinoma cells. Nature. 1999; 398:422-6. https://doi.org/10.1038/18884.

21. Barker N, van Es JH, Kuipers J, Kujala P, van den Born M, Cozijnsen M, Haegebarth A, Korving J, Begthel H, Peters PJ, Clevers H. Identification of stem cells in small intestine and colon by marker gene Lgr5. Nature. 2007; 449:1003-7. https://doi.org/10.1038/nature06196.

22. Zhou X, Michal JJ, Zhang L, Ding B, Lunney JK, Liu $\mathrm{B}$, Jiang Z. Interferon induced IFIT family genes in host antiviral defense. Int J Biol Sci. 2013; 9:200-8. https://doi. org/10.7150/ijbs.5613.

23. Fensterl V, Sen GC. Interferon-induced Ifit proteins: their role in viral pathogenesis. J Virol. 2015; 89:2462-8. https:// doi.org/10.1128/JVI.02744-14.

24. Pichlmair A, Lassnig C, Eberle C, Górna MW, Baumann CL, Burkard TR, Bürckstümmer T, Stefanovic A, Krieger $\mathrm{S}$, Bennett KL, Rülicke T, Weber F, Colinge J, et al. IFIT1 is an antiviral protein that recognizes 5'-triphosphate RNA. Nat Immunol. 2011; 12:624-30. https://doi.org/10.1038/ ni.2048.

25. Li Y, Li C, Xue P, Zhong B, Mao AP, Ran Y, Chen H, Wang YY, Yang F, Shu HB. ISG56 is a negative-feedback regulator of virus-triggered signaling and cellular antiviral response. Proc Natl Acad Sci U S A. 2009; 106:7945-50. https://doi.org/10.1073/pnas.0900818106.

26. Stawowczyk M, Van Scoy S, Kumar KP, Reich NC. The Interferon Stimulated Gene 54 Promotes Apoptosis. J Biol Chem. 2011; 286:7257-66. https://doi.org/10.1074/jbc. M110.207068.

27. Wang J, Park JS, Wei Y, Rajurkar M, Cotton JL, Fan Q, Lewis BC, Ji H, Mao J. TRIB2 Acts Downstream of Wnt/TCF in Liver Cancer Cells to Regulate YAP and C/ EBP $\alpha$ Function. Mol Cell. 2013; 51:211-25. https://doi. org/10.1016/j.molcel.2013.05.013.

28. Skrzypczak M, Goryca K, Rubel T, Paziewska A, Mikula M, Jarosz D, Pachlewski J, Oledzki J, Ostrowsk J, Benson J, Liau S, Ilyas M, Straub J, et al. Modeling Oncogenic
Signaling in Colon Tumors by Multidirectional Analyses of Microarray Data Directed for Maximization of Analytical Reliability. PLoS One. 2010; 5:e13091. https://doi. org/10.1371/journal.pone.0013091.

29. Galamb O, Györffy B, Sipos F, Spisák S, Németh AM, Miheller P, Tulassay Z, Dinya E, Molnár B. Inflammation, adenoma and cancer: objective classification of colon biopsy specimens with gene expression signature. Dis Markers. 2008; 25:1-16. https://doi.org/10.1155/2008/586721.

30. Sabates-Bellver J, Van der Flier LG, de Palo M, Cattaneo E, Maake C, Rehrauer H, Laczko E, Kurowski MA, Bujnicki JM, Menigatti M, Luz J, Ranalli TV, Gomes V, et al. Transcriptome profile of human colorectal adenomas. Mol Cancer Res. 2007; 5:1263-75.

31. Zeng G, Apte U, Cieply B, Singh S, Monga SPS. siRNAmediated beta-catenin knockdown in human hepatoma cells results in decreased growth and survival. Neoplasia. 2007; 9:951-9.

32. Feng $X$, Wang $Y$, Ma Z, Yang $R$, Liang S, Zhang $M$, Song S, Li S, Liu G, Fan D, Gao S. MicroRNA-645, up-regulated in human adencarcinoma of gastric esophageal junction, inhibits apoptosis by targeting tumor suppressor IFIT2. BMC Cancer. 2014; 14:633. https://doi. org/10.1186/1471-2407-14-633.

33. Wang Y, Zhang L, Zheng X, Zhong W, Tian X, Yin B, Tian K, Zhang W. Long non-coding RNA LINC00161 sensitises osteosarcoma cells to cisplatin-induced apoptosis by regulating the miR-645-IFIT2 axis. 2016. https://doi. org/10.1016/j.canlet.2016.08.024.

34. Andersen J, Vanscoy S, Cheng TF, Gomez D, Reich N. IRF-3-dependent and augmented target genes during viral infection. Genes Immun. 2008; 9:168-75. https://doi. org/10.1038/sj.gene.6364449.

35. Levy D, Larnert A, Chaudhuri A, Babiss LE, Darnell JE. Interferon-stimulated transcription: Isolation of an inducible gene and identification of its regulatory region (transfection/ adenoviral vectors/cell surface signals). Biochemistry. 1986; 83:8929-33.

36. Weaver BK, Kumar KP, Reich NC. Interferon Regulatory Factor 3 and CREB-Binding Protein/p300 Are Subunits of Double-Stranded RNA-Activated Transcription Factor DRAF1. Mol Cell Biol. 1998; 18:1359-68.

37. Grandvaux N, Servant MJ, tenOever B, Sen GC, Balachandran S, Barber GN, Lin R, Hiscott J. Transcriptional profiling of interferon regulatory factor 3 target genes: direct involvement in the regulation of interferon-stimulated genes. J Virol. 2002; 76:5532-9. https://doi.org/10.1128/JVI.76.11.5532-5539.2002.

38. Barnes BJ, Richards J, Mancl M, Hanash S, Beretta L, Pitha PM. Global and distinct targets of IRF-5 and IRF-7 during innate response to viral infection. J Biol Chem. 2004; 279:45194-207. https://doi.org/10.1074/jbc.M400726200.

39. Lou YJ, Pan XR, Jia PM, Li D, Xiao S, Zhang ZL, Chen SJ, Chen Z, Tong JH. IRF-9/STAT2 [corrected] functional interaction drives retinoic acid-induced gene $\mathrm{G}$ expression 
independently of STAT1. Cancer Res. 2009; 69:3673-80. https://doi.org/10.1158/0008-5472.CAN-08-4922.

40. Theofilopoulos AN, Kono DH, Beutler B, Baccala R. Intracellular nucleic acid sensors and autoimmunity. J
Interferon Cytokine Res. 2011; 31:867-86. https://doi. org/10.1089/jir.2011.0092. 